\title{
Acer okamotoanum Nakai Leaf Extract Inhibits Adipogenesis Via Suppressing Expression of PPAR $\gamma$ and C/EBP $\alpha$ in 3T3-L1 Cells
}

\author{
Eun-Joo Kim ${ }^{1}$, Min-jae Kang ${ }^{1}$, Yong Bae Seo ${ }^{1,2}$, Soo-Wan Nam ${ }^{3}$, and Gun-Do Kim ${ }^{1 *}$ \\ ${ }^{1}$ Department of Microbiology, College of Natural Sciences, Pukyong National University, Busan 48513, Republic of Korea \\ ${ }^{2}$ Institute of Marine Biotechnology, Pukyong National University, Busan 48513, Republic of Korea \\ ${ }^{3}$ Biomedical Engineering and Biotechnology Major, Division of Applied Bioengineering, College of Engineering, Dong-Eui University, Busan \\ 47230, Republic of Korea
}

\author{
Received: February 1, 2018 \\ Revised: May 29, 2018 \\ Accepted: August 7, 2018 \\ First published online \\ August 10, 2018 \\ *Corresponding author \\ Phone: +82-51-629-5618 \\ Fax: +82-51-629-5619; \\ E-mail: gundokim@pknu.ac.kr \\ pISSN 1017-7825, eISSN 1738-8872 \\ Copyright(C) 2018 by \\ The Korean Society for Microbiology \\ and Biotechnology
}

\begin{abstract}
The genus Acer contains several species with various bioactivities including antioxidant, antitumor and anti-inflammatory properties. However, Acer okamotoanum Nakai, one species within this genus has not been fully studied yet. Therefore, in this study, we investigated the anti-adipogenic activities of leaf extract from A. okamotoanum Nakai (LEAO) on 3T3-L1 preadipocytes. Adipogenesis is one of the cell differentiation processes, which converts preadipocytes into mature adipocytes. Nowadays, inhibition of adipogenesis is considered as an effective strategy in the field of anti-obesity research. In this study, we observed that LEAO decreased the accumulation of lipid droplets during adipogenesis and down-regulated the expression of key adipogenic transcription factors such as peroxisome proliferator-activated receptor $\gamma$ (PPAR $\gamma$ ) and CCAAT/enhancer binding protein $\alpha(\mathrm{C} / \mathrm{EBP} \alpha)$. In addition, LEAO inactivated PI3K/Akt signaling and its downstream factors that promote adipogenesis by inducing the expression of PPAR $\gamma$. LEAO also activated $\beta$-catenin signaling, which prevents the adipogenic program by suppressing the expression of PPAR $\gamma$. Therefore, we found that treatment with LEAO is effective for attenuating adipogenesis in 3T3-L1 cells. Consequently, these findings suggest that LEAO has the potential to be used as a therapeutic agent for preventing obesity.
\end{abstract}

Keywords: Acer okamotoanum, adipogenesis, anti-obesity, 3T3-L1 preadipocytes

\section{Introduction}

Recently, one of the major public health problems in the United States and other advanced countries has been a dramatic increase in obesity [1]. Obesity is the state of energy imbalance caused by the overconsumption of calories and a lack of physical exercise. This condition is a risk factor for numerous chronic illnesses such as hypertension, type II diabetes, cardiovascular disease and stroke [1, 2]. The reasons for obesity include genetic influences, environmental factors and unhealthy lifestyles [3]. In particular, it has been reported that increasing the number or size of mature adipocytes through adipogenesis is closely related to the occurrence of obesity [4].

Adipogenesis is a precisely regulated cell differentiation process that results in conversion of preadipocytes into mature adipocytes. This process is divided into two-step, clonal expansion and terminal differentiation. During clonal expansion, the cells express cell-cycle proteins and prepare to induce expression of specific transcriptional factors including CCAAT/enhancer binding protein $\alpha$ $(\mathrm{C} / \mathrm{EBP} \alpha)$ and peroxisome proliferator-activated receptor $\gamma$ (PPAR $\gamma$ ). Following this step, these two factors lead to terminal differentiation and accumulation of lipid droplets $[5,6]$.

PPAR $\gamma$ and C/EBP $\alpha$ play a crucial role in adipogenesis as master regulators. PPAR $\gamma$ is a nuclear receptor that works in conjunction with the retinoid $X$ receptor (RXR) and induces differentiation by hormonal stimulation $[7,8]$. During the initiation of adipocyte differentiation, both 
C/EBP $\beta$ and C/EBP $\delta$ of C/EBP family are expressed earlier than $\mathrm{C} / \mathrm{EBP} \alpha$. These factors are responsible for induction of C/EBP $\alpha$ and PPAR $\gamma$ expression. Accordingly, PPAR $\gamma$ and C/EBP $\alpha$ not only cross-regulate each other's expression but also control the entire adipogenesis process by activating additional adipogenic transcription factors [6-8].

The adipogenic transcriptional cascade involved in adipogenesis includes $\mathrm{PI} 3 \mathrm{~K} / \mathrm{Akt}$ signaling and $\beta$-catenin signaling. The PI3K/Akt signaling pathway has an essential role in the up-regulation of PPAR $\gamma$ and C/EBP $\alpha$ expression and adipogenesis [9]. Moreover, the mammalian target of rapamycin (mTOR) is an activated downstream factor of Akt and it promotes adipogenesis [10]. On the other hand, $\beta$-catenin signaling represses adipogenesis by blocking expression of PPAR $\gamma$ [11].

Acer okamotoanum Nakai belongs to the family Aceraceae, commonly referred to as maple trees. The genus Acer is comprised of 150 species around the world, mostly distributed in Asia [12]. A. okamotoanum Nakai grows in the mountains of Ullung Island in Korea [13]. Since the hypertension improving effect and hepatoprotective activity of its sap were reported [14, 15], A. okamotoanum Nakai has only been utilized for its sap and the tree itself is hardly used. In addition, Acer species have been reported to possess various biological and pharmacological properties including antioxidant, antitumor and anti-inflammatory effects [12]. Although many studies have already revealed that, the anti-obesity effects of $A$. okamotoanum Nakai have not been studied yet.

Thus, in this study, we investigated the anti-obesity effects of leaf extracts from A. okamotoanum Nakai to identify their potential as functional materials.

\section{Materials and Methods}

\section{Sample Preparation}

The methanol extracts of A. okamotoanum Nakai (EAO), including its different parts, such as leaf (LEAO), root (REAO) and stem (SEAO) were purchased from Korea Plant Extract Bank (KPEB) (Korea). Extracts were diluted in dimethyl sulfoxide (DMSO) (Sigma-Aldrich Inc., USA) to a concentration of $100 \mathrm{mg} / \mathrm{ml}$. The final concentrations of DMSO in all experiments were maintained at less than $0.1 \%$.

\section{Cell Culture}

3T3-L1 preadipocytes derived from mouse embryo were purchased from Korean Cell Line Bank (KCLB, Korea). The cells were cultured in Dulbecco's Modified Eagle's Medium (DMEM) (Cellgro, USA) supplemented with 10\% calf serum (Gibco, USA) and $1 \%$ penicillin-streptomycin (Hyclone, USA). Cells were maintained with a humidified condition of $5 \% \mathrm{CO}_{2}$ at $37^{\circ} \mathrm{C}$. The medium was replaced every 2 days and cells were incubated until pre-confluent.

\section{Cell Viability Assay}

The cytotoxicity of 3T3-L1 cells treated with LEAO, REAO and SEAO was determined by using WST-1 assay. 3T3-L1 preadipocytes were seeded in 96-well cell culture plate $\left(5 \times 10^{3}\right.$ cells/well). After incubation, cells were treated with several concentrations $(25,50$, $75,100,150$, and $200 \mu \mathrm{g} / \mathrm{ml}$ ) of LEAO, REAO, and SEAO for 24 , 48 , and $72 \mathrm{~h}$. After that, the media were replaced with fresh media. $10 \mu \mathrm{l}$ of EZ-cytox Cell Viability Assay Solution WST-1 (Daeil Lab Service, Korea) was added to each well and cells were incubated for $3 \mathrm{~h}$. The absorbance of each well was measured by using a microplate reader (Molecular Devices, USA) at $460 \mathrm{~nm}$.

\section{T3-L1 Preadipocytes Differentiation}

Two days after reaching confluence (day 0), preadipocytes were induced for differentiation by treatment with MDI [10 $\mu \mathrm{g} / \mathrm{ml}$ insulin, 0.5 mM 3-isobutyl-1-methylxanthine (IBMX), $1 \mu \mathrm{M}$ Dexamethasone (Sigma-Aldrich Inc.)] in DMEM containing 10\% fetal bovine serum (FBS) (Cellgro) for 2 days (from day 0 to day 2). After 2 days, the medium was changed with DMEM containing $1 \mu \mathrm{g} / \mathrm{ml}$ insulin and $10 \%$ FBS (from day 2 to day 4 ). On day 4 , the medium was changed again with DMEM containing $0.25 \mu \mathrm{g} / \mathrm{ml}$ insulin and $10 \%$ FBS. On day 6 , the medium was replaced with DMEM containing 10\% FBS and cells were incubated for an additional 2 days. The cells were treated with extracts, LEAO, REAO, and SEAO to examine anti-adipogenic activity during the differentiation process.

\section{Oil Red O Staining}

The influence of LEAO, REAO, and SEAO on lipid droplet generating in 3T3-L1 cells was investigated using the Oil Red O Staining Protocol, after full differentiation (at day 8). Cells were washed with phosphate buffered saline (PBS) (Biosesang, Korea) and fixed with $4 \%$ formaldehyde (Junsei Chemical Co., Ltd., Japan) for $5 \mathrm{~min}$. Formaldehyde was removed and cells were rinsed with $60 \%$ isopropanol (Sigma-Aldrich Inc.). Cells were fixed with $4 \%$ formaldehyde once again for $1 \mathrm{~h}$ and stained with $3.5 \mathrm{~g} / \mathrm{l}$ of Oil Red O (Sigma-Aldrich Inc.) in $60 \%$ isopropanol for $10 \mathrm{~min}$. The stained cells were washed with distilled water and entirely dried. The stained lipid droplets in cells were visualized by using a phase contrast microscope. Furthermore, stained dye was eluted by using $100 \%$ isopropanol and the absorbance was measured at $450 \mathrm{~nm}$ with a microplate reader (Molecular Devices).

\section{Immunofluorescence (IF) Staining}

3T3-L1 cells were seeded on cover-glass bottom dishes (SPL Lifesciences, Korea) and differentiated with or without treatment of LEAO. After adipocyte differentiation, cells were washed with 1X PBS and stained by $1 \mu \mathrm{g} / \mathrm{ml}$ of DAPI in methanol for $20 \mathrm{~min}$ at 
Table 1. Primer sequences for RT-PCR.

\begin{tabular}{cll}
\hline Genes & \multicolumn{1}{c}{ Forward Primers } & \multicolumn{1}{c}{ Reverse Primers } \\
\hline PPAR $\gamma$ & CAAGAATACCAAAGTGCGATCAA & GAGCTGGGTCTTTTCATAATAAG \\
C/EBP $\alpha$ & CTGGAAAGAAGGCCACCTC & AAGAGAAGGAAGCGGTCCA \\
GAPDH & TGTTACCAACTGGGACGACA & GGGGTGTTGAAGCTCTCAAA \\
\hline
\end{tabular}

$37^{\circ} \mathrm{C}$. After incubation, cells were re-washed with PBS and fixed by using $4 \%$ formaldehyde for $10 \mathrm{~min}$ at room temperature. Cells were blocked by blocking solution with $5 \%$ rabbit normal serum (Santa Cruz Biotechnology Inc., USA) containing 0.3\% Triton X100 (Sigma-Aldrich Inc.) in $1 \times$ PBS for $1 \mathrm{~h}$ in dark conditions. Blocked cells were treated with anti-PPAR $\gamma$ primary antibody (Cell Signaling Technology Inc., USA) at $4^{\circ} \mathrm{C}$ for overnight. After that, cells were rinsed with $1 \times$ PBS and incubated with anti-rabbit IgG $(\mathrm{H}+\mathrm{L}), \mathrm{F}\left(\mathrm{ab}^{\prime} 2\right)$ fragment (Alexa Fluor 488 conjugate) (Cell Signaling Technology Inc.) for $1 \mathrm{~h}$ at room temperature in dark conditions. Cells were washed with $1 \times$ PBS and mounted by ProLong Gold Anti-fade Reagent (Invitrogen, USA). The stained cells were observed with a Carl Zeiss LSM 710 confocal laser scanning microscope (Carl Zeiss, Germany).

\section{Western Blot Analysis}

Fully-differentiated cells were washed with ice-cold 1X PBS and then lysed in cell lysis buffer containing $50 \mathrm{mM}$ Tris- $\mathrm{Cl}$ ( $\mathrm{pH} 7.5)$, $150 \mathrm{mM} \mathrm{NaCl}, 1 \mathrm{mM}$ DTT, $0.5 \%$ NP-40, 1\% Triton X-100, 1\% deoxycholate and $0.1 \%$ SDS (Intron Biotechnology, Korea) at $4^{\circ} \mathrm{C}$ for $30 \mathrm{~min}$. To collect the supernatants, the lysates were centrifuged at $14,000 \mathrm{rpm}$ for $20 \mathrm{~min}$ at $4^{\circ} \mathrm{C}$. The protein concentration in lysates was measured by Bradford reagent (Biosesang, Seongnam, Korea). Equal amounts of proteins were separated by $12 \%$ SDSpolyacrylamide gel electrophoresis. The proteins were transferred to nitrocellulose membranes (Pall Life Sciences, USA). The membranes were blocked with 5\% skim milk in 1X PBST buffer $\left(135 \mu \mathrm{M} \mathrm{NaCl}, 2.7 \mathrm{mM} \mathrm{KCl}, 4.3 \mathrm{mM} \mathrm{NaPO}_{4}, 1.4 \mathrm{mM} \mathrm{KH}_{2} \mathrm{PO}_{4}\right.$ and $0.5 \%$ Tween-20) for $1 \mathrm{~h}$. After blocking, the membranes were washed with $1 \mathrm{X}$ PBST and incubated with primary antibodies such as GAPDH, $\beta$-actin, PPAR $\gamma, \mathrm{C} / \mathrm{EBP} \alpha$, fatty acid synthase, adiponectin, PI3K110 $\alpha$, PI3K110 $\beta$, PI3K110 $\delta$, Akt, phospho-Akt (Ser 473), mTOR, phospho-mTOR (Ser 2481), P70S6K, phosphorP70S6K (Ser 371), $\beta$-catenin, phospho- $\beta$-catenin (Ser 552 or Ser 33,37/Thr 41), GSK3 $\beta$, phospho-GSK3 $\beta$ (Ser 9) (1:1000) (Cell Signaling Technology Inc.) or SREBP1 (1:1000) (Abcam, UK) for overnight at $4^{\circ} \mathrm{C}$. The membranes were washed with $1 \mathrm{X}$ PBST and incubated with HRP-linked anti-rabbit secondary antibody (Cell Signaling Technology Inc.) for $1 \mathrm{~h}$ at room temperature. The membranes were developed on X-ray film using enhanced chemiluminescent (ECL) detection solution (Pierce, USA). Intensity comparisons were quantified by using Image-J software (National Institutes of Health).

\section{Reverse Transcription Polymerase Chain Reaction (RT-PCR)}

Total RNA from 3T3-L1 cells was extracted by using RNeasy Plus Mini Kit (Qiagen, Germany). The concentration of total RNA was measured by nanodrop (MECASYS, Korea) and $2 \mu \mathrm{g}$ of total RNA was used to synthesize the cDNA using AccuPower RT PreMix (Bioneer, Korea). An equal volume of cDNA was amplified $\left(95^{\circ} \mathrm{C}\right.$ for $30 \mathrm{sec}, 55^{\circ} \mathrm{C}$ for $30 \mathrm{sec}$, and $72^{\circ} \mathrm{C}$ for $30 \mathrm{sec}, 33 \mathrm{cycle}$ ) by Prime Tag Premix (Genetbio, Korea) with specific primers, such as PPAR $\gamma, \mathrm{C} / \mathrm{EBP} \alpha$, and GAPDH (Table 1). The amplified PCR products were visualized by $2 \%$ agarose gel. Intensity comparisons
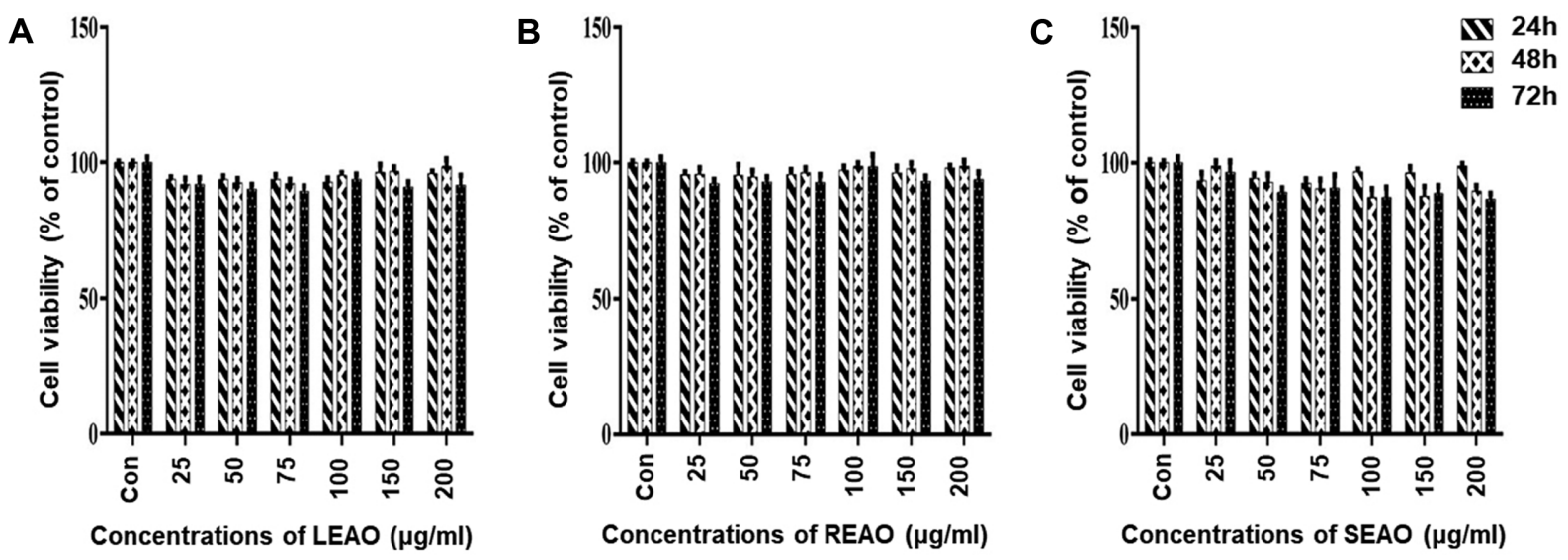

Fig. 1. Effects of A. okamotoanum Nakai extracts on cell viability in 3T3-L1 cells.

Cells were treated with several concentrations of (A) LEAO, (B) REAO, and (C) SEAO for 24, 48, and $72 \mathrm{~h}$. The cell viability was measured by WST-1 assay. All values in the graph are represented as mean \pm SD and experiments were performed independently and in triplicate. 
were quantified by using Image-J software (National Institutes of Health).

\section{Statistical Analysis}

All experiments were performed independently and in triplicate. Data were presented as the mean \pm standard deviation (SD). Differences between the mean values of each group were analyzed by two-way analysis of variance (ANOVA) with Dunnett's multiple-comparison test. The statistical significance of data was analyzed by Graph Pad Prism 6.0 software (GraphPad, USA). P values were considered as statistical significance.
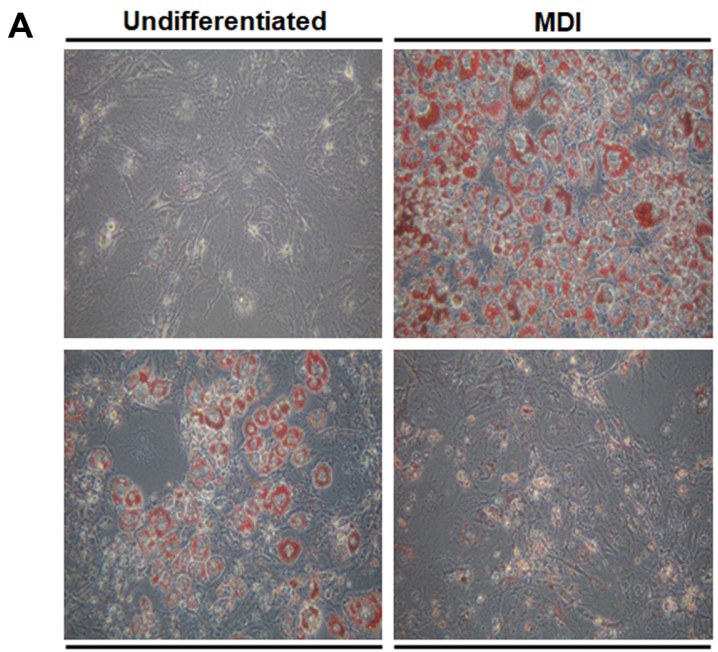

MDI + LEAO $50 \mu \mathrm{g} / \mathrm{ml}$
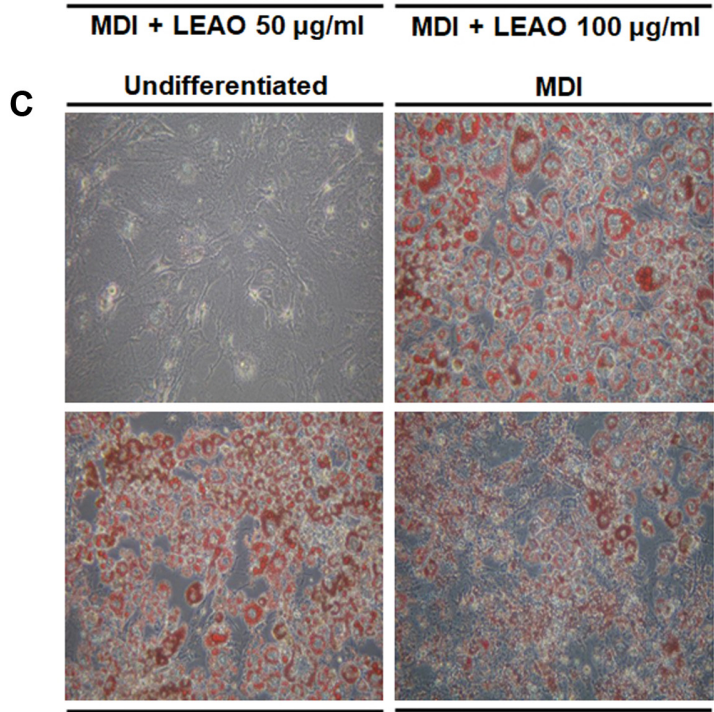

MDI + SEAO $50 \mu \mathrm{g} / \mathrm{ml}$

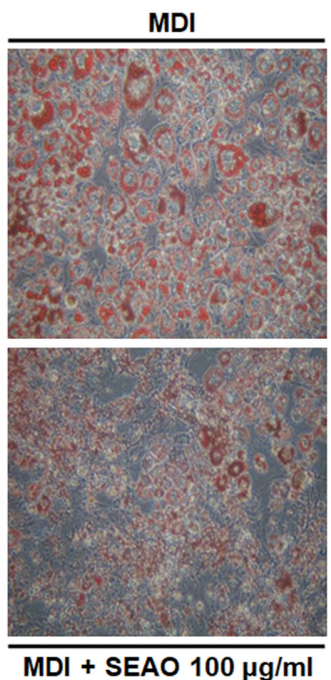

\section{Results}

Effects of LEAO, REAO, and SEAO on Cell Viability in 3T3-L1 Preadipocytes

To evaluate the cytotoxicity of LEAO, REAO, and SEAO in 3T3-L1 cells, cell viability was determined by WST-1 assay. The cells were treated with various concentrations of LEAO, REAO, and SEAO for 24,48 , and $72 \mathrm{~h}$. As shown in Fig. 1, cell viability was not significantly decreased up to $200 \mu \mathrm{g} / \mathrm{ml}$ of all extracts treated for $72 \mathrm{~h}$. Thus, further

B
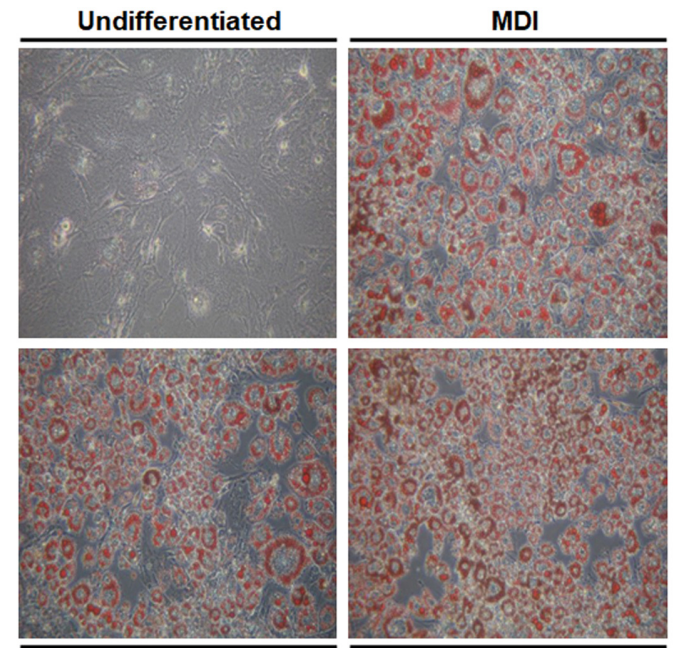

MDI + REAO $50 \mu \mathrm{g} / \mathrm{ml}$

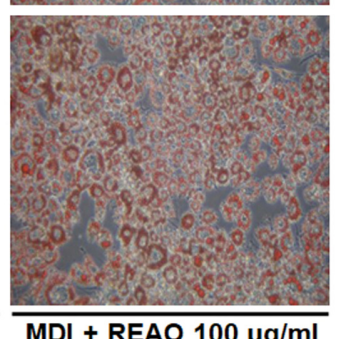

D

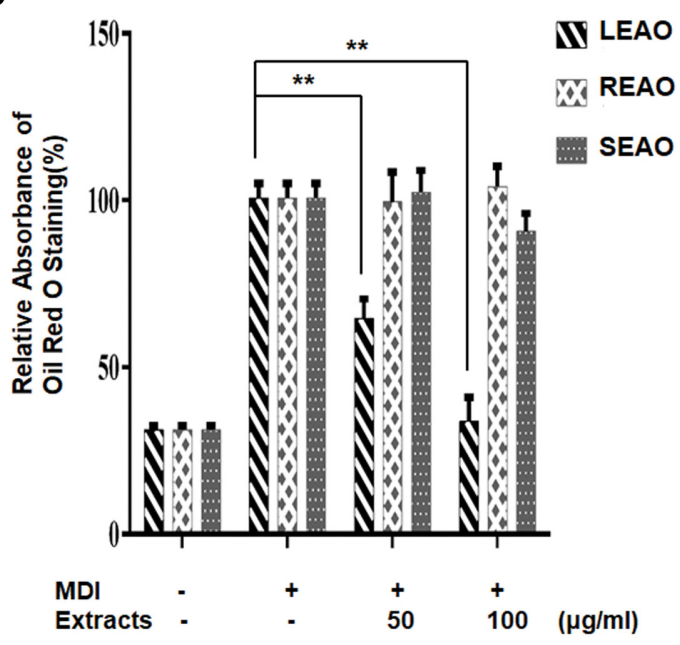

Fig. 2. Effects of A. okamotoanum Nakai on adipocyte differentiation in 3T3-L1 cells.

After growing to confluence, adipocyte differentiation was induced by treatment with MDI (mixture of IBMX, dexamethasone and insulin) containing 10\% FBS for 8 days. The cells were incubated in the absence or presence of 50 and $100 \mu \mathrm{g} / \mathrm{ml}$ of LEAO, REAO and SEAO. (A), (B), and (C) After induction of differentiation, cells were stained with Oil Red $\mathrm{O}$ and visualized by phase contrast microscope (magnification of $\times 100$ ). (D) The quantifications of retained Oil Red O dyes were determined by spectrophotometric analysis. Each value in graphs is expressed as mean \pm SD $(n=3) .{ }^{* *} P<0.01$ indicates statistical significances compared to the fully-differentiated control cells. 
studies were implemented at concentrations of extracts under $200 \mu \mathrm{g} / \mathrm{ml}$.

Effects of LEAO, REAO, and SEAO on Adipocyte Differentiation in 3T3-L1 Preadipocytes

To examine the inhibitory effect of LEAO, REAO, and SEAO on lipid accumulation, differentiated cells with or without two concentrations (50 and $100 \mu \mathrm{g} / \mathrm{ml}$ ) of LEAO, REAO, and SEAO were observed by Oil Red O staining. First, LEAO dramatically suppressed lipid accumulation in 3T3-L1 cells dose-dependently, relative to entirely differentiated cells (Fig. 2A). Meanwhile, REAO did not have inhibitory effect on adipocyte differentiation (Fig. 2B). As shown in Fig. 2C, SEAO was less effective at reducing lipid droplet-containing cells than the LEAO. These results indicate that LEAO inhibited adipocyte differentiation in 3T3-L1 cells more so than REAO and SEAO (Fig. 2D). Thus, LEAO was only used for further studies.

Effects of LEAO on the Expression of Key Adipogenic Transcription Factors

To elucidate effect of LEAO on the expression of key adipogenic markers at transcriptional and translational levels, we performed RT-PCR and western blot, respectively. The mRNA levels of PPAR $\gamma$ and C/EBP $\alpha$ were decreased by LEAO in a dose-dependent manner, compared with fully-differentiated control cells (Fig. 3A). As presented in Fig. 3B, both protein expressions of PPAR $\gamma$ and C/EBP $\alpha$ were significantly decreased by LEAO. Furthermore, to examine the nuclear translocation of PPAR $\gamma$, we executed immunofluorescence staining with $100 \mu \mathrm{g} / \mathrm{ml}$ of LEAO treatment. As a result, PPAR $\gamma$ was translocated to the nucleus in differentiated control cells, but the nuclear translocation of PPAR $\gamma$ was clearly reduced in LEAOtreated cells (Fig. 3C).

\section{Effects of LEAO on the Expression of Lipogenic Factors Related to Adipogenesis}

Furthermore, western blot analysis was used to investigate the effects of LEAO on the expression of adipogenesisrelated factors. These factors include sterol regulatory element binding protein (SREBP1), fatty acid synthase and adiponectin. As shown in Fig. 4, we found that LEAO treatment dramatically reduced the protein expressions of
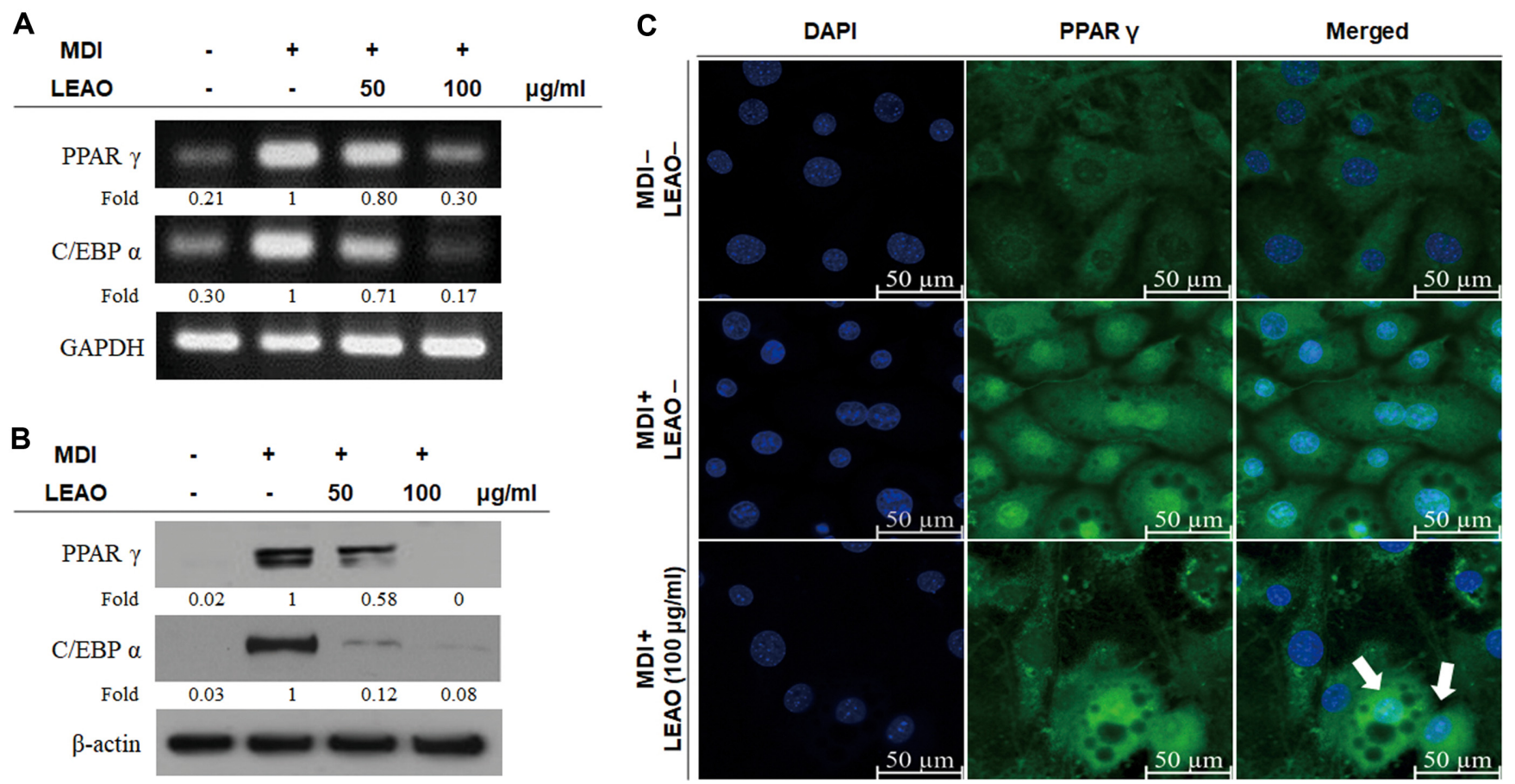

Fig. 3. Effects of LEAO on the expressions of key adipogenic transcription factors.

(A) and (B) After treatment for 8 days, the expressions of PPAR $\gamma$ and C/EBP $\alpha$ at mRNA and protein levels. The expression levels of mRNA and protein were detected by RT-PCR and western blot analysis, respectively. GAPDH and $\beta$-actin were used as a loading control. Fold changes indicate the expression ratio compared with fully-differentiated cells. (C) Effects of LEAO on nuclear translocation of PPAR $\gamma$. It was analyzed by immunofluorescence staining and observed by confocal microscopy (blue: DAPI and green: PPAR $\gamma$ ). Arrows in figure indicate that the nuclear translocation of PPAR $\gamma$ was lower than the differentiated control cells. (Scale bar, $50 \mu \mathrm{m}$ ). 


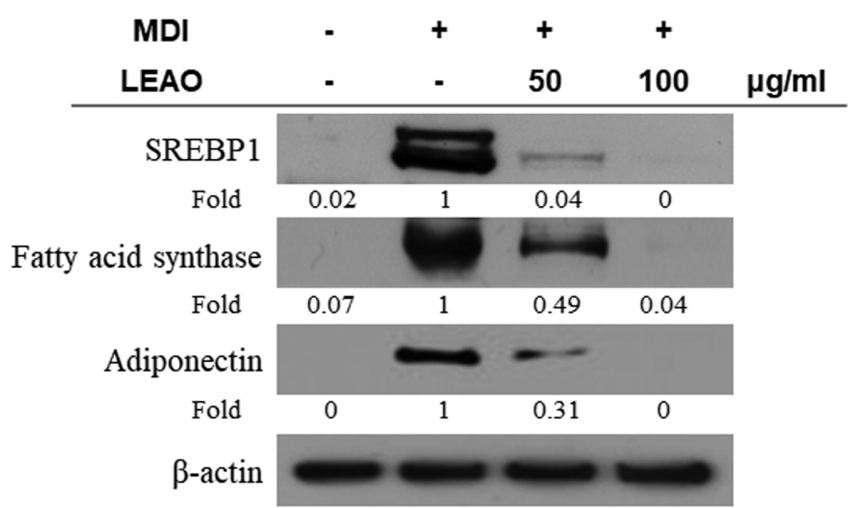

Fig. 4. Effects of LEAO on the expressions of lipogenic factors related to adipogenesis.

After adipocyte differentiation with LEAO treatment, the protein expression levels of SREBP1, fatty acid synthase and adiponectin were examined by western blotting. $\beta$-actin was used as a loading control. Fold changes indicate the expression ratio compared with fully-differentiated cells.

SREBP1, fatty acid synthase and adiponectin, relative to differentiated control cells.

\section{Effects of LEAO on the Regulation of PI3K/Akt Signaling}

To examine the further mechanism of LEAO on antiadipogenic activity, we investigated whether LEAO can modulate the PI3K/Akt signaling pathway. As presented in Fig. 5A, LEAO substantially decreased the expression levels of phosphoinositide 3-kinase (PI3K) 110 $\alpha$ subunit,

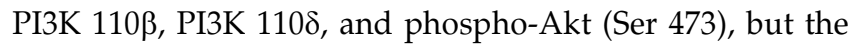
protein expression of total Akt was not affected. Fig. 5B shows that the protein expression of phospho-mTOR (Ser 2481) was significantly decreased, like the inhibition effect of phospho-Akt (Ser 473) expression. Also, phospho-P70S6K (Ser 371), a downstream signaling protein of mTOR, was extremely down-regulated in $100 \mu \mathrm{g} / \mathrm{ml}$ of LEAO-treated cells. Meanwhile, LEAO did not affect the total protein expression levels of either mTOR or P70S6K.

\section{Effects of LEAO on the Regulation of $\beta$-Catenin Signaling}

To identify whether LEAO regulates some components of the $\beta$-catenin signaling pathway, we performed western blot analysis. As seen in Fig. 6, LEAO up-regulated expression levels of $\beta$-catenin and phospho- $\beta$-catenin (Ser 552). In contrast, the expression level of phospho- $\beta$-catenin (Ser 33, 37/Thr 41) was significantly decreased in a dosedependent manner. Moreover, the treatment of LEAO increased the expression levels of phospho-GSK3 $\beta$ (Ser 9), while it didn't affect expression of total GSK3 $\beta$.

\section{Discussion}

Many studies have lately reported that bioactive compounds from natural products have shown inhibitory
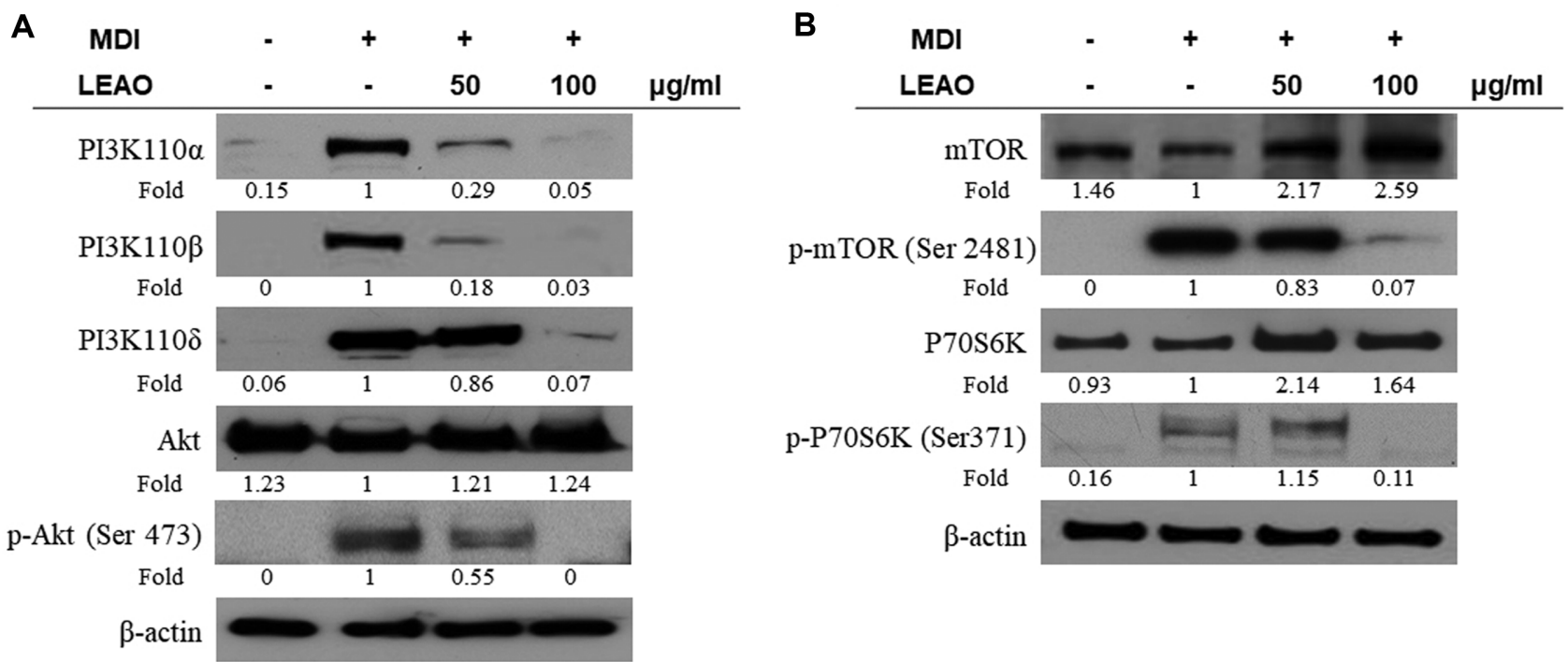

Fig. 5. Effects of LEAO on the regulation of PI3K/Akt signaling pathway.

Proteins were extracted from 3T3-L1 cells at day 8 after induction of adipogenesis with the presence or absence of LEAO. Western blot analysis was performed to examine the PI3K/Akt signaling pathway. (A) The protein expression levels of PI3K 110 $\alpha$, PI3K 110 3 , PI3K 1108, Akt and p-Akt (Ser 473). (B) The protein expression levels of mTOR, p-mTOR (Ser 2481), P70S6K and p-P70S6K. $\beta$-actin was used as a loading control. Fold changes indicate the expression ratio compared with fully-differentiated cells. 


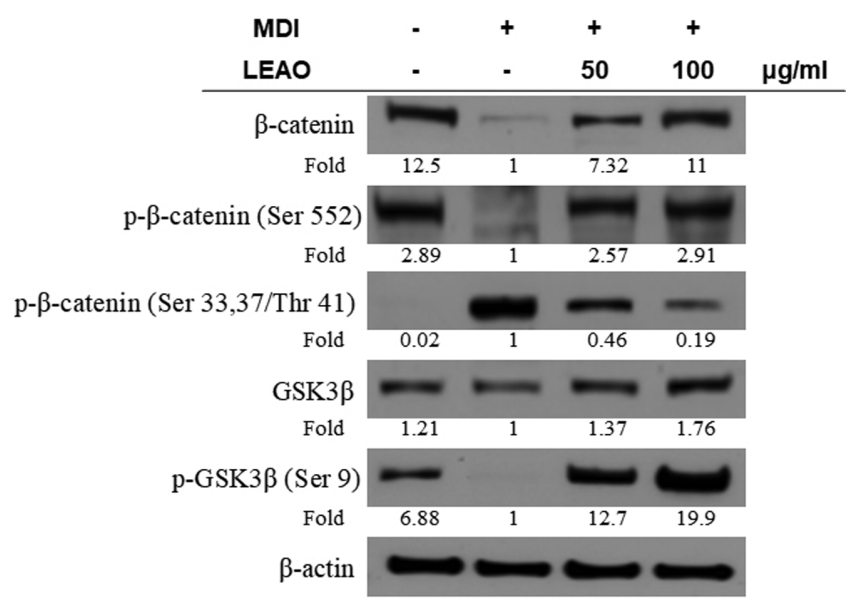

Fig. 6. Effects of LEAO on the regulation of $\beta$-catenin signaling pathway.

The cells were treated with or without LEAO for 8 days. After adipocyte differentiation, total proteins were extracted and then the protein expression levels of $\beta$-catenin, $p$ - $\beta$-catenin (Ser 552$), p-\beta$-catenin (Ser 33, 37/Thr 41), GSK3 $\beta$ and p-GSK3 $\beta$ (Ser 9) were detected using western blotting. $\beta$-actin was used as a loading control. Fold changes indicate the expression ratio compared with fully-differentiated cells.

effect on adipocyte differentiation, which is drawing attention as an attractive approach for anti-obesity treatment [16-18]. In this study, we demonstrated that LEAO is able to suppress adipogenesis through modulation of adipogenic pathways including PI3K/Akt signaling and $\beta$-catenin/ GSK3 $\beta$ signaling. Above all, treatment with LEAO downregulated the expressions of master transcription factors in the adipogenesis such as PPAR $\gamma$ and C/EBP $\alpha$.

The molecular interactions between PPAR $\gamma$ and C/EBP $\alpha$ are essential for the entire adipogenic program. PPAR $\gamma$ directly regulates adipogenesis, whereas adipogenic activity of C/EBP $\alpha$ depends on the presence of PPAR $\gamma$. Nevertheless, $\mathrm{C} / \mathrm{EBP} \alpha$ is required for retaining expression of PPAR $\gamma$ and promoting full insulin sensitivity. This transcription cascade maintains the terminally differentiated state by inducing high levels of each other's expression in a positive feedback loop $[5,19,20]$. The obtained results showed that the expression levels of adipogenic markers, both PPAR $\gamma$ and C/EBP $\alpha$, were significantly reduced and the translocation of PPAR $\gamma$ into the nucleus was inhibited by LEAO (Fig. 3). These findings indicated that LEAO effectively attenuated adipocyte differentiation through inhibiting expressions of master transcription factors.

SREBP1 is involved in energy homeostasis by controlling lipogenesis and required for adipogenesis by constructing PPAR $\gamma$ ligands. The activated SREBP1 up-regulates lipogenic genes expression and improves fatty acid synthesis [21, 22]. The major constituent of lipids in adipose tissue is synthesized by fatty acid synthase. Fatty acid synthase also plays a significant role in energy homeostasis by converting energy to lipid storage [23]. In addition, adiponectin, which is secreted from adipose tissue, promotes adipocyte differentiation and increases lipid accumulation as well as insulin sensitivity [24]. As shown in Fig. 2, LEAO treatment displayed drastically decreasing lipid accumulation during adipogenesis. We also found that the expression levels of SREBP1, fatty acid synthase and adiponectin were decreased by LEAO treatment in a dose-dependent manner (Fig. 4). These results demonstrate that LEAO suppressed lipid accumulation during adipocyte differentiation through down-regulation of lipogenic factors.

The PI3K/Akt signaling pathway is associated with insulin receptors, which increases glucose uptake and stimulates differentiation in adipocytes [9]. Insulin initiates an adipogenic signaling cascade and activates PI3K p110 isoforms [25]. The activated PI3K produces phosphatidylinositol-3-phoasphate $\left(\mathrm{PIP}_{3}\right)$, which provides binding site of the pleckstrin homology $(\mathrm{PH})$ domains in other signaling proteins. Akt possessed PH domain, which directly interacts with $\mathrm{PIP}_{3}$. When Akt is combined with $\mathrm{PIP}_{3}$, it causes recruitment and catalytic activation of Akt $[9,26,27]$. Ultimately, activated Akt induces expression of PPAR $\gamma$ at the initiation of adipocyte differentiation [28]. In our results (Fig. 5A), we found that LEAO inhibited the activation of the PI3K/Akt signaling pathway, resulting in blocking metabolic actions of insulin, like lipid synthesis.

A major downstream branch of Akt, mTOR is involved in the regulation of PPAR $\gamma$ expression and required for proper adipocyte differentiation [29]. Not only controlling PPAR $\gamma$ expression, mTOR controls lipogenesis through up-regulating the expression of SREBP1 related to lipid biosynthesis [30]. P70S6K is a downstream effector of mTOR and it promotes growth and development of adipose tissue by its phosphorylation [31]. Our results indicate that LEAO treatment inhibited the phosphorylation of mTOR and P70S6K by attenuating the PI3K/Akt pathway (Fig. 5B).

GSK3 $\beta$ is a key component of $\beta$-catenin signaling and inactivated via phosphorylation of its serine 9 residue. $\beta$-catenin is phosphorylated at Ser-33,37/Thr-41 residues by GSK3 $\beta$ and then subjected to ubiquitination and degraded by the proteasome $[32,33]$. On the contrary, the inhibition of GSK3 $\beta$ activity leads to increasing cytoplasmic $\beta$-catenin levels. When $\beta$-catenin is phosphorylated at serine 552 residue, it translocates to the nucleus [34, 35]. This phosphorylation promotes the transcriptional activity of 


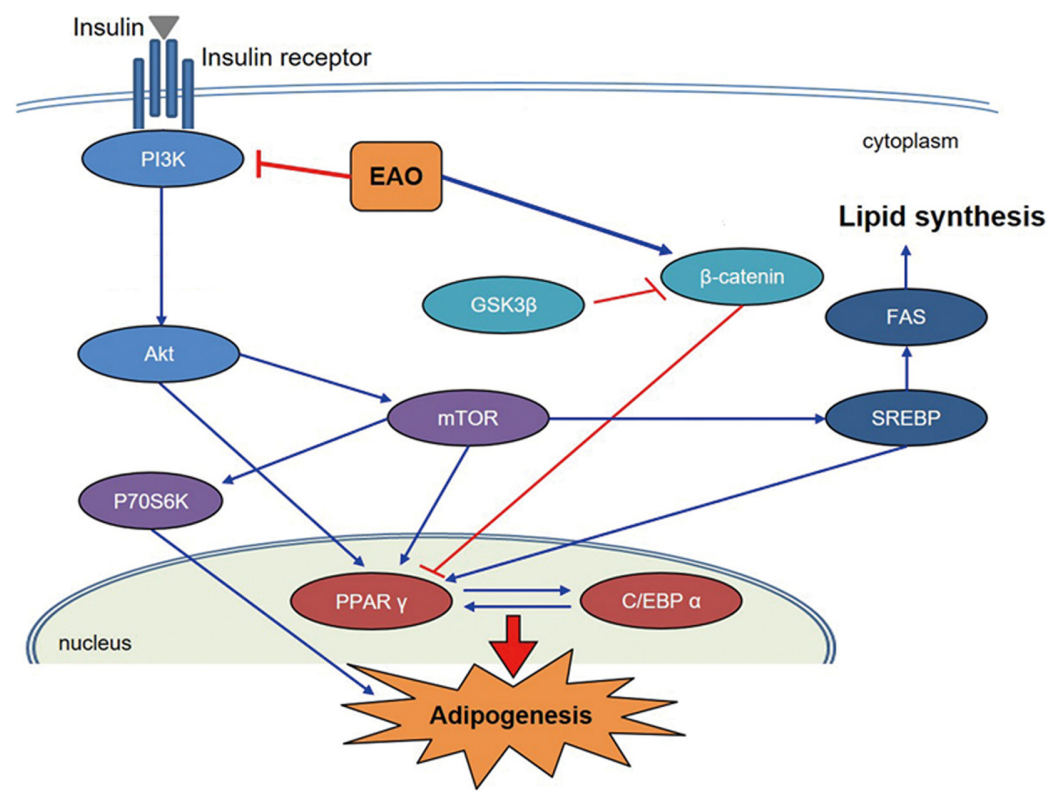

Fig. 7. Schematic diagram of possible molecular mechanism of LEAO in adipogenesis.

$\beta$-catenin and means the activation of $\beta$-catenin [36]. $\beta$ catenin is one of the negative regulators in adipogenesis through inhibiting the transcriptional activity of PPAR $\gamma$ [37]. Our findings showed that treatment with LEAO induced the activation of $\beta$-catenin. Moreover, the phosphorylation of $\beta$-catenin was decreased at Ser-33,37/Thr-41 residues through inhibition of GSK3 $\beta$ by its phosphorylation at serine 9 residue in LEAO treated cells (Fig. 6). These results indicated that the $\beta$-catenin pathway modulated the activation of PPAR $\gamma$ due to LEAO treatment.

In summary, possible anti-adipogenic mechanisms of LEAO on 3T3-L1 cells are displayed as a schematic illustration to support understanding (Fig. 7). The LEAO treatment exhibits the anti-adipogenic effects through suppressing the expression of PPAR $\gamma$ and C/EBP $\alpha$, and regulation of several signaling pathways including the PI3K/Akt signaling cascade and the $\beta$-catenin pathway. To conclude, LEAO showed inhibitory effects on adipocyte differentiation of 3T3-L1 cells. On the basis of these data, this study suggests that the LEAO could be used as an alternative therapeutic agent to prevent and ameliorate obesity.

\section{Acknowledgments}

This research was a part of the project title 'Development and commercialization of bio-active and color-improved substrate for aquaculture animals using Korea-specific chromogenic marine microorganisms,' funded by the Ministry of Oceans and Fisheries, Korea.

\section{Conflict of Interest}

The authors have no financial conflicts of interest to declare.

\section{References}

1. Pi-Sunyer FX. 2002. The obesity epidemic: pathophysiology and consequences of obesity. Obesity 10: 97S-104S.

2. Lawrence VJ, Kopelman PG. 2004. Medical consequences of obesity. Clin. Dermatol. 22: 296-302.

3. Marti A, Moreno-Aliaga M, Hebebrand J, Martinez J. 2004. Genes, lifestyles and obesity. Int. J. Obes. 28: S29-S36.

4. Spiegelman BM, Flier JS. 1996. Adipogenesis and obesity: rounding out the big picture. Cell 87: 377-389.

5. Ali AT, Hochfeld WE, Myburgh R, Pepper MS. 2013. Adipocyte and adipogenesis. Eur. J. Cell Biol. 92: 229-236.

6. Farmer SR. 2006. Transcriptional control of adipocyte formation. Cell Metabolism. 4: 263-273.

7. Rosen ED, MacDougald OA. 2006. Adipocyte differentiation from the inside out. Nature Reviews. Mol. Cell Biol. 7: 885-896.

8. Rosen ED, Sarraf P, Troy AE, Bradwin G, Moore K, Milstone DS, et al. 1999. PPAR $\gamma$ is required for the differentiation of adipose tissue in vivo and in vitro. Mol. Cell 4: 611-617.

9. Saltiel AR, Kahn CR. 2001. Insulin signalling and the 
regulation of glucose and lipid metabolism. Nature 414: 799806.

10. Laplante M, Sabatini DM. 2012. mTOR signaling in growth control and disease. Cell 149: 274-293.

11. Christodoulides C, Lagathu C, Sethi JK, Vidal-Puig A. 2009. Adipogenesis and WNT signalling. Trends Endocrinol. Metab. 20: $16-24$.

12. Bi W, Gao Y, Shen J, He C, Liu H, Peng Y, et al. 2016. Traditional uses, phytochemistry, and pharmacology of the genus Acer (maple): a review. J. Ethnopharmacol. 189: 31-60.

13. Jin L, Han JG, Ha JH, Jeong HS, Kwon MC, Jeong MH, et al. 2008. Comparison of antioxidant and glutathione S-transferase activities of extracts from Acer mono and A. okamotoanum. Korean J. Med. Crop Sci. 16: 427-433.

14. Yang H, Hwang I, Koo TH, Ahn HJ, Kim S, Park MJ, et al. 2012. Beneficial effects of Acer okamotoanum sap on L-NAMEinduced hypertension-like symptoms in a rat model. Mol. Med. Rep. 5: 427-431.

15. Yoo Y, Jung E, Kang H, Choi I, Choi K, Jeung E. 2011. The sap of Acer okamotoanum decreases serum alcohol levels after acute ethanol ingestion in rats. Int. J. Mol. Med. 28: 489-495.

16. Rayalam S, Della-Fera MA, Baile CA. 2008. Phytochemicals and regulation of the adipocyte life cycle. J. Nutr. Biochem. 19: 717-726.

17. Yun JW. 2010. Possible anti-obesity therapeutics from naturea review. Phytochemistry 71: 1625-1641.

18. Feng S, Reuss L, Wang Y. 2016. Potential of natural products in the inhibition of adipogenesis through regulation of PPAR $\gamma$ expression and/or its transcriptional activity. Molecules 21: 1278.

19. Farmer S. 2005. Regulation of PPAR [gamma] activity during adipogenesis. Int. J. Obes. 29: S13-S16.

20. Rosen ED, Hsu CH, Wang $X$, Sakai S, Freeman MW, Gonzalez FJ, et al. 2002. C/EBPalpha induces adipogenesis through PPARgamma: a unified pathway. Genes Dev. 16: 22-26.

21. Eberlé D, Hegarty B, Bossard P, Ferré P, Foufelle F. 2004. SREBP transcription factors: master regulators of lipid homeostasis. Biochimie 86: 839-848.

22. Kim JB, Spiegelman BM. 1996. ADD1/SREBP1 promotes adipocyte differentiation and gene expression linked to fatty acid metabolism. Genes Dev. 10: 1096-1107.

23. Chirala SS, Wakil SJ. 2004. Structure and function of animal fatty acid synthase. Lipids 39: 1045-1053.

24. Fu Y, Luo N, Klein RL, Garvey WT. 2005. Adiponectin promotes adipocyte differentiation, insulin sensitivity, and lipid accumulation. J. Lipid Res. 46: 1369-1379.

25. Whitehead JP, Clark SF, Ursø B, James DE. 2000. Signalling through the insulin receptor. Curr. Opin. Cell Biol. 12: 222-228.

26. Khan A, Pessin J. 2002. Insulin regulation of glucose uptake: a complex interplay of intracellular signalling pathways. Diabetologia 45: 1475-1483.

27. Sasaki T, Takasuga S, Sasaki J, Kofuji S, Eguchi S, Yamazaki M, et al. 2009. Mammalian phosphoinositide kinases and phosphatases. Prog. Lipid Res. 48: 307-343.

28. Zhang HH, Huang J, Düvel $\mathrm{K}$, Boback B, Wu S, Squillace $\mathrm{RM}$, et al. 2009. Insulin stimulates adipogenesis through the Akt-TSC2-mTORC1 pathway. PLoS One 4: e6189.

29. Kim JE, Chen J. 2004. Regulation of peroxisome proliferatoractivated receptor-gamma activity by mammalian target of rapamycin and amino acids in adipogenesis. Diabetes 53: 2748-2756.

30. Laplante M, Sabatini DM. 2009. An emerging role of mTOR in lipid biosynthesis. Curr. Biol. 19: R1046-R1052.

31. Fox HL, Kimball SR, Jefferson LS, Lynch CJ. 1998. Amino acids stimulate phosphorylation of p70S6k and organization of rat adipocytes into multicellular clusters. Am. J. Physiol. 274: C206-C213.

32. Wu D, Pan W. 2010. GSK3: a multifaceted kinase in Wnt signaling. Trends Biochem. Sci. 35: 161-168.

33. Taurin S, Sandbo N, Qin Y, Browning D, Dulin NO. 2006. Phosphorylation of beta-catenin by cyclic AMP-dependent protein kinase. J. Biol. Chem. 281: 9971-9976.

34. Grimes CA, Jope RS. 2001. The multifaceted roles of glycogen synthase kinase $3 \beta$ in cellular signaling. Prog. Neurobiol. 65: 391-426.

35. Ding VW, Chen RH, McCormick F. 2000. Differential regulation of glycogen synthase kinase 3beta by insulin and Wnt signaling. J. Biol. Chem. 275: 32475-32481.

36. Fang D, Hawke D, Zheng Y, Xia Y, Meisenhelder J, Nika H, et al. 2007. Phosphorylation of beta-catenin by AKT promotes beta-catenin transcriptional activity. J. Biol. Chem. 282: 1122111229.

37. Liu J, Farmer SR. 2004. Regulating the balance between peroxisome proliferator-activated receptor gamma and betacatenin signaling during adipogenesis. A glycogen synthase kinase 3beta phosphorylation-defective mutant of betacatenin inhibits expression of a subset of adipogenic genes. J. Biol. Chem. 279: 45020-45027. 